\title{
Intraoperative Nerve Monitoring
}

National Cancer Institute

\section{Source}

National Cancer Institute. Intraoperative Nerve Monitoring. NCI Thesaurus. Code

C143030.

The use of electrophysiological methods to evaluate the functional integ rity of neural structures during surgery. 